\title{
Antropología e Historia. Por un diálogo interdisciplinar
}

En este ciclo sobre la "Antropología y otras disciplinas sociales", se trata de contribuir a la definición de las fronteras que separan o unen a la antropología con varias ciencias conexas. Naturalmente, se intenta explorar los territorios vecinos, no aquellos que llevan a una relación con ciencias lejanas, con las cuales puede haber una conexión puramente metafórica. Ese sería el caso, por ejemplo, de la que hay con la astronomía, con la cual ha sido comparada la antropología reiteradamente por Lévi-Strauss, en virtud de que nuestra disciplina se ocupaba originariamente de pueblos primitivos y lejanos, como la astronomía se ocupaba de los astros, seres alejados de la tierra. Pues bien, en nuestro caso particular es todo lo contrario, pues la relación de la antropología con la historia pertenece al tipo de fronteras entre ciencias verdaderamente vecinas, por no decir hermanas. Ya veremos qué tipo de consecuencias diferentes se producen en la comparación con disciplinas cercanas.

Normalmente, esta comparación entre ciencias vecinas ha tenido un cariz de contraste, si no de agresión mutua: eso suele ocurrir en el caso de materias afines mucho más que en el de las que tienen una relación infrecuente. Ni más ni menos ocurre en el mundo natural, que cuando dos animales suelen consumir el mismo tipo de alimentos se repelen, al coincidir en el mismo territorio: la naturaleza se encarga de que los seres iguales no habiten densamente un mismo hábitat, con el fin de que no esquilmen los recursos naturales, siempre limitados. La vecindad siempre es más cómoda con los seres compatibles - aunque diferentes- que con los iguales, resultando por definición rivales. Esto hizo tan agresivas las relaciones en los años sesenta entre antropología y sociología, o incluso entre antropología y folklore, y más tarde con la filosofía (con la que competíamos estrechamente en la búsqueda de plazas de profesorado universitario). Algo parecido a lo que había ocurrido entre la antropología y la arqueología en los treinta; aunque de modo más complejo, porque la etnología podía cumplir - además de la simple suplantación- funciones complementarias para la arqueología, y viceversa.

Ahora bien, estas comparaciones más o menos agresivas, tendían también a establecer una consciencia de identidad muy viva en las disciplinas 
concernidas. Los antropólogos salían de estos debates fratricidas más convencidos de su identidad, y unidos entre sí por tener enemigos comunes. No se trataba naturalmente de realidades 'absolutas', sino de cuestiones al nivel de la consciencia - movidas a veces, como se ha visto, por simples intereses-. De hecho, una mirada rápida a la situación variada de la antropología en España, Francia, Inglaterra, Alemania o Estados Unidos nos demuestra que las fronteras entre una disciplina y otra no son para nada las mismas. Frente a la división insalvable entre la antropología física y la cultural que predomina en Europa, en Estados Unidos esta disciplina parecía ser realmente un saber enciclopédico de ambas ramas, conteniendo además la lingüística y la arqueología. Y ello evoluciona a su vez en cada lugar con el paso del tiempo, como queda claro en EE.UU. en la actualidad, con la implantación progresiva de la división european en departamentos biológicos, lingüísticos, arqueológicos y etnográficos. En la actualidad podemos decir, por tanto, que hay una variedad considerable de 'tradiciones' antropológicas, que tiene que ver tanto con las diferentes disciplinas que componen o han formado parte de la antropología $\longrightarrow$ de su entorno cercano-, como con las diferentes formas en que se han cultivado y relacionado éstas en cada país, a través del tiempo.

Por ello, me propongo analizar la cuestión de la identidad antropológica, enfocando la relación entre ella y otras disciplinas dentro de un tiempo, no como una situación estable. Por otro lado, y concediendo que existe a lo largo del tiempo y de las tradiciones nacionales una identidad diferenciada de la antropología, por comparación con la historia, sin embargo voy a tomar en cuenta también las semejanzas y parentescos que pueda haber entre ellas. Es más, desde ahora anuncio que mi posición va a ser enfatizar éstas sobre las diferencias o discontinuidades. Mi estrategia, si cabe, será mostrar primeramente algunas definiciones de ambas disciplinas, en forma tentativa. Luego abordaremos, en forma histórica, algunos problemas derivados de la comparación y la relación entre ellas.

\section{A MODO DE DEFINICIONES}

Hace falta un esbozo definitorio de una disciplina, antes de proceder a cualquier comparación o conexión con otra. Naturalmente, no pretendemos por nuestra parte agotar ahora los elementos de identificación, ni convencer a todo el mundo del carácter sistemático de nuestras definiciones. Solamente tratamos de establecer un punto de comparación entre la antropología y la historia, y para ello nos valdremos de los criterios que 
nos parecen más compartidos, al menos en la tradición occidental y europea que ha influído en España.

El primer elemento que suele emplearse para caracterizar a la antropología como disciplina diferencial es su objeto de estudio. Por mucho que ya no se corresponda con la realidad actual - en que todas las sociedades del mundo son objeto de la antropología, incluso las grandes urbes como tales conjuntos, según la pretensión más reciente- ${ }^{1}$, el objeto tradicional de conocimiento antropológico han sido los pueblos primitivos, sin los cuales esta disciplina no sería hoy como es. Su tamano pequeño permitió estudios globales por una sola persona, en un plazo breve de tiempo. Su propia lejanía de Occidente obligó al aprendizaje de su lengua, y a la adaptación personal a condiciones nuevas de vida. Su peligro de extinción dotó a esta disciplina del hálito filantrópico que la caracteriza, y tinó sus trabajos del carácter de estudio de urgencia" para salvar la cultura, antes de su desaparición física, con que se distinguen los estudios primeros de nuestra disciplina. Así como también se justificó - por tal urgencia, por el exotismo y por el pequeño tamaño- el tipo de conocimiento enciclopédico (a medias entre la geografía, la economía, la sociología, la filología y la historia de las religiones) con que se ha desarrollado. Todo ello, sin contar los conocimientos botánicos, zootécnicos, biológicos, dietéticos, etc., que eran, a veces, necesarios para describir una comunidad de estudio antropológico.

Estas mismas cualidades disciplinares pueden trasplantarse al tratamiento antropológico de las propias poblaciones aldeanas, que también fueron objeto de interés de parte de las sociedades antiguas de folklore, en donde participaron algunos de nuestros conocidos personajes (Tylor, Frazer, Boas, Kroeber, Van Gennep, Machado, Costa, etc.); aunque la cercanía cultural respecto del observador, su mayor tamaño como comunidades, la impronta occidental sufrida largamente, etc., le hacen menos eficaz para haber contribuido a la definición disciplinar en los orígenes de la disciplina. A pesar de que comparten efectivamente con la tradición exoticista muchas de sus cualidades (interdisciplinariedad, filantropía, arcaismo, relativismo cultural, viaje al campo, etc.), no son bastantes sus propios condicionamientos de contexto como para 'definir' la antropología ${ }^{2}$. A este respecto, acudiré a Lévi-Strauss para ahorrarme hacer énfasis propios a la

1 Ver, por ejemplo, las nuevas propuestas dentro del campo de la antropología urbana. Cf. los trabajos de José Luis García, Juan José Pujadas, María Cátedra y Francisco Cruces /Ángel Díaz de Rada en la Sesión primera sobre *Antropología Urbana*, de las II Jormadas de Antropología de Madrid (1991: 39-111).

2 Ver el trabajo adjunto de Carmen Ortiz sobre antropología y folklore, para mayores precisiones. 
hora de señalar la importancia de los pueblos primitivos como objeto de estudio antropológico, diferente por ejemplo al conocimiento sociológico o al folklórico (es decir, de sociedades cercanas al investigador):

Es en la medida que las sociedades primitivas están muy apartadas de la nuestra como podemos llegar en ellas a esos 'hechos de funcionamiento general' de que hablaba Mauss, que bien pudieran ser 'más universales' y tener 'mayor realidad'. En esas sociedades se captan hombres, grupos y comportamientos, se los ve moverse como en mecánica, se ven masas y sistemas (1986: 31).

Bien es verdad que la sociedad primitiva era más bien una 'construcción' que una realidad: es decir, que los antropólogos del siglo xix y parte del XX han manejado en sus obras una imagen simplificada, construida a partir de 'amputaciones' imaginarias - sociedades sin estado, sin escritura, sin historia... - respecto de la propia sociedad, como sostiene Adam Kuper (1988) convincentemente, y con gran sentido crítico. Pero, a pesar de esta arbitrariedad, es un hecho peculiar de la disciplina, reconocido por el propio Kuper, que esta 'construcción' ideológica ha durado demasiado tiempo, y ha dominado muy generalmente a la antropología occidental, hasta el punto de constituir ahora un signo de identidad.

En los años sesenta, se intentó superar esta limitación del objeto de conocimiento por parte de un sector joven, y se pusieron de moda las denuncias contra la limitación de los estudios de comunidad - por oposición a los 'estudios de área' norteamericanos, o a las consideraciones sociales de mayor espacio por parte de la sociología, la geografía o la historia-. A los estudios de comunidad - por su carácter microsocial y de control unipersonal- se les acusó incluso de estar 'asociados' al proyecto colonial, al intento de control y disgregación de las unidades sociales previas a la llegada occidental: en todo caso, es evidente que tales sociedades se hallaban en los confines de los imperios europeos, y no eran accesibles a los países sin colonias ${ }^{3}$.

3 Ver a este respecto el tomo 2 de la colección Anagrama de Antropología, dirigida por J. R. Llobera (1975). Lo más substancioso del coordinador no era el prólogo sino el epílogo, un Post-scriptum titulado *Algunas tesis provisionales sobre la naturaleza de la Antropología", donde se 'demostraba' axiomáticamente - a lo Althuser- que el objeto de estudio especializado en los pueblos primitivos era una prueba clara del carácter ideológico colonial de la antropología, en particular de la inglesa. La que, por su misma composición ideológica (= ciencia al servicio del capitalismo, apud MarxAlthuser) era pragmática, y poco sofisticada teóricamente. Tras haber 'hipostasiado' así la versión inglesa de la antropología, se proponía que la antropología, qua antropología, era 'ideológica' y no científica. Menos mal que se trataba de una hipótesis 'provisional'... Me he ocupado de esta asociación antropología = colonialismo en $\mathrm{F}$. del Pino (1991). 
También se propuso entonces, de modo relativamente perentorio en la generación joven, substituir en la disciplina el estudio de los pueblos primitivos y exóticos por el de las 'sociedades campesinas', a las cuales la intelectualidad neo-marxista (retorno a Marx joven, y al troskismo = contra Stalin) tornaba a dedicarles la mirada de interés, a la espera de un nuevo sector 'revolucionario'. Es bien conocido que el mundo obrero occidental comenzaba entonces a incorporarse al 'estado del bienestar' y a la sociedad de consumo, olvidando toda propuesta revolucionaria y centrando sus acciones sindicales en reformas parciales del sistema. Quedaba entonces como única puerta de transformación total -aparte los grupos universitarios de vanguardia (Berkeley, París, Francfort...)- el mundo campesino, al que la ortodoxia marxista -especialmente la staliniana - había condenado como clase naturalmente 'reaccionaria' y adscrita a la propiedad de la tierra y a las relaciones de 'servidumbre' medievales. Entonces, las migraciones masivas del campo a la ciudad que tenían lugar en las zonas subdesarrolladas, permitían esperar se diese un recurso revolucionario en la población rural, como de hecho ocurrió en contadas regiones de Asia y América Latina. De ahí, la unión entre 'guerrilleros' estudiantes y campesinos en busca de tierra y trabajo, tan frecuente en el imaginario universitario del 68 , admirador de figuras paradigmáticas como Mao Tse Tung o Che Guevara por buscar la revolución en el campo.

En América Latina se impuso en los círculos renovadores el cambio de nombre $\longrightarrow$ de indio a campesinom - para referirse a la realidad objeto de estudio del antropólogo, e incluso algunos personajes relevantes como José María Arguedas fueron considerados en Perú por sus colegas como 'retardatarios' del avance disciplinar, por adscribirse tenazmente al 'estudio del indio' y rechazar el ideal del 'indio aculturado', que perseguían en esa época los institutos indigenistas americanos: en virtud de sus experiencias infantiles con el mundo andino, y el dominio de la lengua, Arguedas superaba en calidad etnográfica a la mayor parte de sus colegas universitarios, pero no se sentía tan seguro ante las nuevas ideas que dominaban a nivel mundial en la profesión. En 1965 fue enjuiciada muy duramente su novela Todas las sangres, no como novela sino como obra de un antropólogo: no había comprendido que ya no había indios sino campesinos, y que su salvación en el mundo contemporáneo no consistía en su mantenimiento como tales dentro de una sociedad plural - per se 'retardataria' del propuesto desarrollo nacional - sino en su aculturación. La problemática personal del autor -que había encontrado una salvación temporal a sus crisis neuróticas en la escritura literaria y en la antropológica- se acrecentó hasta impedirle seguir escribiendo en sus dos 
especialidades, y terminaría buscando solución desesperada en el suicidio a fines del 69 (lo había intentado ya en 1966). Sin embargo, Arguedas no era ningún tipo de personaje inadaptado o reaccionario, sino alguien en quien se depositaban confianzas públicas en su país, y un autor premiado en Cuba, y casado en segundas nupcias con una estudiante chilena prochina $^{4}$.

No es ocioso decir ahora que otro antropólogo suicida, Paul Mercier, cuando se hizo eco -en su conocido manual histórico- del espíritu rousseauniano que caracteriza a todo antropólogo -que busca lo exótico de los primitivos, insatisfecho de su sociedad, como declaraba de sí mismo Malinowski-, y tras repetir la famosa humorada de Margared Mead sobre el antropólogo como insatisfecho de sí mismo (como el psicólogo) y de su sociedad (como el sociólogo)", lo asumía abiertamente como prueba clara de lo difícil que es separar una antropología científica de otra cargada de sentimientos personales. Pero, a continuación, y de modo harto disgustado y distante -diría uno-, agregaba:

Sin embargo, actualmente se está formando una nueva generación de antropólogos, para la cual la acción - sobre el 'subdesarrollo'- parece una motivación más importante (1969: 216) ?

Volviendo al punto inicial -de las definiciones antropológicas-, además del objeto de estudio habría que agregar otras características

- Para un esclarecimiento de estos detalles, ver la serie de documentos que acompañan la edición crítica de Eve-Marie Fell -llena de correspondencia epistolar y análisis literarios- de la novela (interrumpida por su suicidio), Arguedas (1990), publicada en la colección internacional Archivos, en la que participa por España el CSIC. Así mismo hay abundantes textos suyos y documentos en Rovira (1992). Del homenaje colectivo coordinado por Julio Ortega (1983), destacamos el artículo de su amigo John V. Murra: José María Arguedas: dos imágenes•, pp. 43-54. Soy deudor de la tesis de bachiller en la Universidad Católica de Lima, de Carmen Pinilla sobre Arguedas antropólogo (en prensa), donde se contiene un detenido análisis del debate de 1965 en el Instituto de Estudios Peruanos.

5 Se refiere naturalmente a la generación del 68, que denunciaba en París el interés científico y el romanticismo antropológico como contrario a los intereses humanos del Tercer Mundo, al que había que salvar del capitalismo occidental. Es curioso que otro antropólogo que consideraba su deber dedicarse al estudio de los pueblos primitivos como Alfred Metraux - siendo el principal inspirador de Lévi-Strauss, que dirige el homenaje que le rindió su revista L'Homme a su muerte- eligiese igualmente el suicidio en 1963. Dos seguidores suyos como Pierre Clastres y Thierry Saignes murieron también jóvenes, y algunos han interpretado su muerte como un suicidio 'intencional'. El propio Lévi-Strauss (1961) se hacía eco previamente de esta situación dramática del antropólogo occidental. 
definitorias: aunque es posible que se deriven también de su peculiar objeto de estudio. La principal de ellas es la exigencia de 'totalidad' que debe tener el estudio: debe pretenderse incluir a todos los miembros de la comunidad, en todas sus facetas, desde todos los puntos de vista y, sobre todo, evitando interpretar los datos desde fuera. No basta con estudiar a los líderes o a un sector de población, en una faceta particular, o solamente desde un breve período de su vida, o desde un punto de vista particular. A este respecto es ejemplar la propuesta de M. Mauss de que busquemos en nuestro estudio los 'hechos sociales totales', aquellos en que se contengan todos los niveles de estudio posibles (económico, político, religioso...): así le llamó al principio de reciprocidad descubierto por él en la 'ley del regalo', al comparar la institución del potlatch de la costa noroeste norteamericana (estudiada principalmente por Boas) y la del kula, que regulaba el comercio y la sociabilidad de las islas Trobriand (recién estudiadas por Malinowski, 1922). Puede decirse que este Ensayo sobre el regalo, de 1925, es una de las obras cumbres de la disciplina, no solamente por apoyarse sobre los datos de los dos etnógrafos más prestigiosos del gremio, sino por proponer un modo de estudio 'total', y dar así con un principio central en la vida social de las comunidades tradicionales, el de la reciprocidad.

En todo caso, debe reconocerse que este criterio definitorio no es descriptivo sino ideal: no es que los antropólogos hagan todos eso -más bien, es un caso excepcional - sino que creen todos que deben hacerlo. La realidad cotidiana se impone a la larga, y hoy día se vive en un momento especialmente laxo $-\mathrm{e}$ incluso crítico-, al reconocerse de modo general la excepcionalidad del cumplimiento con las normas profesionales: eso ha dado lugar a la famosa crítica post-modernista. A partir de numerosas figuras (como C. Geertz, James Clifford, G. Marcus, S. Tyler, etc.) se ha reconocido enfáticamente la enorme carga de subjetividad, de parcialidad y de imaginación que hay en los trabajos etnográficos, de modo que es ya difícil mantener la fe en la objetividad científica, y en el logro del 'conocimiento total', antes perseguido como meta inextinguible del gremio. No es el momento de extenderse en ello, pero tampoco conviene pasar por alto este debate sobre la 'identidad de la antropología' cuando se trata de la definición disciplinar. En los propios EE.UU. han suscitado una gran resistencia dentro del gremio estas críticas, como si atentasen contra la cientificidad antropológica, puesta en duda. Pero las críticas principales vienen de Europa.

Entre nosotros, ha sido otra vez nuestro compatriota Josep R. Llobera (profesor de antropología en Londres) quien, a través de un libro premiado por la misma editorial (1990), nos advierte del peligro que la antropología 
post-moderna y anglosajona -especialmente la yanqui, donde predomina el postmodernismo- significa para la pervivencia científica de la disciplina. Si en su primera publicación de 1975 "sobre la naturaleza de la antropología" (antes citada), se nos advertía contra la falta de teorización inglesa como la escoria ideológica natural del capitalismo, ahora se nos previene contra el colonialismo antropológico norteamericano: en ambos casos con pasión desbordada y, al mismo tiempo, con una enorme generosidad informativa y agudeza intelectual.

En varios sentidos, creo que la situación en la historiografía es diferente. Porque, en primer lugar, no se ocupa en ningún caso de los pueblos primitivos ni siquiera de las sociedades muy diferentes, sino de la propia sociedad y, a veces, de sectores minoritarios de la misma. La historia originariamente solía ocuparse de los reyes y personajes importantes -que son quienes más documentos proporcionan-. Por otra parte, la historia se nutre generalmente de materiales documentales, archivados o conservados en las librerías: aunque es verdad que más recientemente, incluye a personajes sin relevancia -incluso marginales-y pretende sobrepasar la limitación del material documental, acudiendo a 'fuentes indirectas' que le transmitan informaciones orales - que no quedaron recogidas, al menos por sus propios actores-, en lo cual se acerca a la antropología.

Ahora bien, cuando decimos que esta disciplina histórica se separa de la otra es - por lo que respecta a España- más bien en cuanto a su posición favorable ante las corrientes que vienen del mundo anglosajón: en ambos casos hay una diferente receptividad (por ejemplo, la obra de historiadores hispanistas ingleses como Elliott es muy apreciada), motivada posiblemente por la menor diferencia de cultivo que hay entre la historiografía española y la extranjera, que entre la antropología española y anglosajona. Frente a la antigüedad disciplinar de la historia en España, la antropología apenas cuenta con una o dos generaciones de practicantes profesionales, y las cátedras de antropología se inician en los años setenta. En el caso de los estudios etnográficos hay, además, el riesgo de que las fronteras nacionales o regionales se vuelvan operativas para cuestionar la validez de los análisis de un colega extranjero: la obra de Pitt-Rivers, por ejemplo, ha sido cuestionada por antropólogos andaluces, a pesar de que se trata del primer trabajo de campo profesional en España, de 1950. Y lo mismo, la de los colegas norteamericanos en Andalucía: una posición que no fue considerada anómala en el reciente Congreso Europeo de Sociología Rural ${ }^{6}$. Con lo que resulta que no se

6 Cf. Isidoro Moreno (1986). El comentario de un testigo es: -Este trabajo causó una verdadera conmoción en el congreso, y la discusión de que fue objeto es recordada vívidamente por aquellos que la presenciaron-, Davydd Greenwood (1992: 31 ). 
trataría simplemente de una distancia 'profesional', sino de otra de tipo más difícil de salvar, de una distancia 'política'. Y no se trataría únicamente de un problema español, sino incluso europeo, por relación al coloso norteamericano: no solamente en el sentido nacional, sino también profesional.

Dentro del mundo antropológico las cosas van un poco más difíciles para la colaboración internacional que en la historia. Es posible que se trate a la larga de un problema de maduración, debido al carácter reciente de la antropología como disciplina internacional: las primeras cátedras europeas son las inglesas del último cuarto del siglo XIX (Tylor en Oxford). Porque hace solamente dos siglos, por ejemplo, la publicación de la History of America (1777) de W. Robertson -al año siguiente de la independencia de las trece colonias del Norte de América, y haciéndose eco de ambas Américas, en justificación de la política inglesa- desencadenó una pequeña guerra en la Academia Espanola de la Historia, entre Campomanes (que fue substituído, finalmente, por apoyarla) y Muñoz (nombrado cronista de Indias en 1775), y todo un affaire de alta política que condujo al nombramiento de Muñoz como encargado de redactar una Historia del Nuevo Mundo en 1779 (que saldrá en 1793, el primer tomo), tras la reunión de un corpus documental gigantesco en la Academia (la Colección Muñoz), además de la erección en 1785 del Archivo General de Indias, por obra de Muñoz (Ballesteros, 1942).

Es posible que las materias disciplinares necesiten de una maduración profesional, antes de que sea posible superar las barreras políticas y nacionales. De todas maneras, es dudoso que alguna vez se obtenga del todo tal maduración, y que no sigan incidiendo en toda colaboración interdisciplinar los problemas no disciplinares. Especialmente en las materias humanísticas.

\section{COINCIDENCIAS Y COLABORACIONES}

Como dije al principio, me propongo desarrollar en esta ocasión no tanto las distancias como las vecindades entre la antropología y la historia. Creo que, por otra parte, de su relación ya se ha hablado suficientemente como para no requerir demasiadas precisiones sistemáticas y tratamientos generales: $\sin$ ir más lejos, en un curso titulado Treinta Lecciones de Etnografía (IX Curso de Etnología), dictado en este mismo Departamento de Antropología en el año 1989 (entonces solamente Programa de Investigación en Tradiciones Populares, dentro del Instituto de Filología), ya se incluían tres lecciones sobre antropología e historia, a cargo del profesor 
Luis Ángel Sánchez Gómez '. Por otro lado, nuestro venerado Caro Baroja ha producido una obra abultada entre la antropología y la historia - reclamada desde ambas instancias con la misma legitimidad-, para llamarse a la sorpresa cuando queremos ahora relacionar ambas disciplinas.

Hemos llamado 'coincidencias' a las realizaciones hechas en cada una de las disciplinas, que le han acercado más a la otra. Como muestra representativa, nos referiremos ahora solamente a dos, una en cada campo. Dentro de la antropología -especialmente norteamericana- se ha creado una subdisciplina llamada Etnobistoria, donde claramente se ha practicado la historia por antropólogos; y dentro de la historiografía -especialmente francesa- ha habido una subdisciplina llamada Antropología Histórica, que es una especie de historia antropológica practicada por historiadores. Merece la pena contemplar la versión realmente practicada de colaboración, antes de abordar algunas discusiones al respecto, enunciadas desde el interior de cada disciplina.

Tratándose en el caso de la antropología del estudio de pueblos sin escritura, la posibilidad de una historia dependía del hallazgo de documentos ajenos: éste es el caso de las fuentes greco-latinas sobre el territorio mediterráneo y norteafricano conocido, de las fuentes árabes sobre los pueblos africanos y asiáticos, de las chinas sobre el área de influencia asiática, etc. Sin embargo, las fuentes más comúnmente usadas por los antropólogos han sido las producidas abundantemente por los pueblos europeos sobre todo el orbe visitado: deben ahora destacarse las fuentes españolas sobre América, que han sido particularmente numerosas. Y esta riqueza se ha debido a varios factores: desde la propia costumbre administrativa española de provocar numerosas informaciones sobre un territorio lejano (afortunadamente satisfecha por un deseo privado muy hispano de dejar constancia de los propios méritos), hasta la feliz curiosidad norteamericana por la propia historia de sus poblaciones indígenas, y de las sudamericanas, territorio más cercano.

Curiosidad provocada tanto por un afán de tener una historia nacional propia por parte de un país joven, como por la conocida tendencia historicista de la antropología norteamericana, especialmente a partir de Boas. Gracias a esta atracción americana por su pasado, se ha podido aprovechar mejor el espléndido Archivo General de Indias, reunido en Sevilla desde el siglo XVIII por obra de Muñoz. El uso de este archivo por parte norteamericana procede de comienzos de siglo, alentado en parte por la visita de 1910 a la Universidad de California del catedrático de

Te conservan ejemplares de aquellas conferencias, dictadas de Enero a Mayo de 1989 por la transcripción directa realizada en el Departamento, de 326 pp., que ha sido reproducida en ciclostil. Las conferencias que nos interesan ocupan las pp. 36-54. 
Oviedo D. Rafael Altamira, en gesto de buena concordia historiográfica y política. Pero la Etnohistoria americana no se consolida como subdisciplina hasta después de la Segunda Guerra Mundial, con la publicación en los años cincuenta de la revista Etbnobistory (Bloomington, Indiana).

En el plano metodológico, el problema a superar era primeramente el de las naturales 'desviaciones' etnocéntricas de las fuentes, debido a su procedencia externa. Además del viejo problema de la escasez y dispersión de información, sobre pueblos muchas veces desaparecidos, se añadía el de su interpretación adecuada. Para ello no había más remedio que utilizar las precauciones generales y, en todo caso, las derivadas del previo conocimiento particular del área cultural: de ahí la ventaja de contar con documentos de pueblos supervivientes, de los que hubiera una etnografía disponible.

Otra veces, había que compensar esta ausencia notable con un buen conocimiento del contexto histórico y biográfico del autor: de ahí han surgido los tratados de "historiografía indiana", con amplia dependencia de los estudios historiográficos (manuales de E. Feuter, Sánchez Alonso, Esteve Barba, o Porras Barrenechea) y de los estudios históricos introductorios a las ediciones de fuentes, por parte de García Icazbalceta, Edmundo O'Gorman, Guillermo Lohman, Pérez de Tudela, etc. Incluso debemos reconocer que para estos estudios se dependía de un especialista en crítica literaria, como es el caso de Rolena Adorno o Mercedes LópezBaralt para Huamán Poma, Pupo-Walker para Cabeza de Vaca, José J. Arrom para Fr. Ramón Pané, José Anadón para Alonso de Erzilla, José Durand o Margarita Zamora para el inca Garcilaso, etc.

Naturalmente, también los antropólogos etnohistoriadores se han tenido que poner manos a la obra en el estudio biográfico de los autoresfuentes (W. Fenton con Lafitau para Canadá, Jiménez de la Espada con Betanzos o Polo de Ondegardo para Perú, C. Araníbar con Cieza, P. Duviols con Francisco de Ávila o Cristóbal de Albornoz para Perú -y recientemente con Juan de Santa Cruz-, Juan Osio o Franklin Pease con Huamán Poma, León Portilla o Manuel Ballesteros con Bernardino de Sahagún para México central, Alfred Tozzer con Landa para Yucatán, etc. $\mathbf{A}$ veces ha habido una estrecha asociación de antropólogos con un historiador o un crítico literario para lograr este control etnohistórico: éste es el caso reciente, por ejemplo, de Rolena Adorno con John V. Murra para la edición crítica de Huamán Poma. O un poco antes, el de Duviols con Arguedas o José Durand para conocer a Francisco de Ávila o Garcilaso. O del propio Adolph F. Bandelier, hace ya un siglo, con el historiador hispano-mexicano Icazbalceta para conocer varias crónicas mexicanas (Tezozomoc, Ixtlilxótlil, y Durán) y poder ayudar al pro- 
pio Lewis $\mathrm{H}$. Morgan a conocer el México antiguo a través de las fuentes españolas.

Es evidente que los intereses del antropólogo no son los mismos que los de su colega historiador a la hora de abordar un documento o escrito antiguo. Normalmente, el antropólogo busca confirmar sus teorías, o completar la información etnográfica de que dispone; al contrario que el historiador, que tiene un interés particular en el autor o documento en sí. Lo que no quiere decir que dos antropólogos tengan los mismos intereses a la hora de utilizarlo: por ejemplo, Julian H. Steward empleó la mucha información histórica reunida sobre las culturas sudamericanas en su Handbook (1946-49) ${ }^{8}$, para apuntalar su 'teoría de la evolución cultural', mientras que su colaborador principal Alfred Metraux seguía elaborando monografías de culturas americanas particulares, y admirándose luego en la UNESCO -su destino posterior- del atractivo intrínseco de cada una, en particular de las culturas amazónicas. Lo mismo cabría decir del material histórico-etnográfico sobre Andalucía, reunido muy pocos años después para la misma institución norteamericana por Julio Caro en colaboración con George Foster: mientras éste elaboraba un libro con una 'teoría de la cristalización cultural', nuestro paisano tomaba simplemente notas etnográficas para monografías aisladas, recientemente reunidas por su colaborador Antonio Carreira (1993) 9 .

Por lo que respecta al uso de la antropología hecho por parte de los historiadores, enunciamos antes una escuela, más o menos propiamente llamada, de "antropología histórica" dentro de la historiografía francesa (ése es el nombre con que se anuncia actualmente en algunos de los cursos de la Ecole des Hautes Etudes en Sciences Sociales). Esta ha surgido entre los seguidores de la famosa "escuela de los Annales», la revista fundada en 1929 por Marc Bloch y Lucien Febvre con el subtítulo «d'histoire sociale», que en 1946 cambiará por «histoires, économies, societés, civi-

\& Continúa siendo la referencia más sólida como manual de la etnografía sudamericana.

9 Naturalmente, no todas las publicaciones de este libro pertenecen a esa colaboración con $G$. Foster, aunque casi todas se inician en ese viaje. Aparte de todo, quedó una memorable monografía sobre Los Moriscos del Reino de Granada (1957), que era el interés de sus pocas visitas previas a Andalucía. Caro era consciente del diferente uso que hicieron ambos de los datos reunidos en el viaje (1993: 10). Solamente Foster actuó como etnohistoriador, al parecer. El libro elaborado por G. Foster (1962) fue traducido, pero es poco conocido en España. En 1953 publicó un artículo en Southwestem Journal of Anthropology, IX: 1, que sería traducido en Perú (1959) y también es poco divulgado en España. El promotor de esta traducción peruana fue José Maria Arguedas, que también trabajó en España en 1958, pero no en Andalucía sino en Sayago (Zamora). 
lisations* (finalmente, Annales, E.S.C.). Normalmente se considera que las tendencias etnológicas de la revista se adscriben en la segunda etapa, de acuerdo al nuevo concepto de 'sociétés, civilisations' incluido significativamente en el subtítulo. Sobre todo es conocida, de su líder en esta segunda etapa Ferdinand Braudel, su amistad con Lévi-Strauss -compañero del Collège de France y de l'Ecole-, a quien cita frecuentemente, haciéndose eco de sus propuestas 'estructuralistas' y de su interés por el inconsciente, que buscan los fenómenos que no varían ni cambian, los de larga duración. También se interesaba en Lévi-Strauss por los 'modelos' interpretativos que proponía como distintos de la propia realidad social, a su vez estructurada (recuérdese la diferencia con el estructuralismo inglés), así como por su intento de hallar una fórmula matemática, que uniese la antropología con la lingüística y la semiología ('matemática social'). Esta influencia —entre otras naturalmente, pero es el autor más citado en el trabajo-, le llevó en 1958 a escribir un famoso y largo artículo sobre la "larga duración" en la revista Annales (1968: 60-106).

Esta estrategia de larga, media y corta duración la había llevado a cabo Braudel desde su tesis doctoral de 1946 sobre El Mediterráneo... de Felipe II, y luego en su obra capital sobre Civilización material y capitalismo. Los acontecimientos de corta duración eran descritos en la parte final, tras los de media o generacionales y los de larga, de tipo más ecológico y cíclico, que precedían el conjunto descriptivo. En esta reflexión sobre los distintos tiempos de la historia, distintos pero coincidentes en la realidad, había una genuina concepción antropológica: no solamente en medir las estructuras de larga duración (lo más próximo a Lévi-Strauss, alérgico a la historicidad en general, como se queja reiteradamente Braudel), sino en la petición de 'totalidad' para el escenario que se requería para la historiografía. Una totalidad que en Braudel se refería no solamente al escenario sino a las anteojeras múltiples desde donde contemplarlo, o sea interdisciplinarmente. Era esa 'totalidad' del saber lo que envidiaba particularmente Braudel en la antropología.

Posteriormente a Braudel, la influencia de Lévi-Strauss y de la escuela de Mauss y Durkheim - sus maestros - ha seguido manifestándose en la obra de personalidades como Leroy Ladurie, G. Duby, J. Le Goff, Natham Wachtel, Roger Chartier, M. De Certau, etc. Una serie larga de autores que manejan estudios sobre poblaciones rurales, sobre sectores marginados o mundos imaginarios, además de ocuparse de la historia social europea. El campo privilegiado de estos trabajos es -aparte de la historia cuantitativa y la documentación seriada, su marca de escuela - el de las 'mentalidades': con un sentido doble, individual y social, consciente e inconsciente. La 
realidad del historiador no está dada sino que 'se construye', y eso se hace tanto por el historiador como por los sujetos históricos.

Todo esto parece haber sido un fenómeno nuevo de los años de postguerra. Y sin embargo, algunos autores sostienen que estos planteamientos derivan de comienzos de siglo, con la obra de Henry Berr alrededor de la Revue de Synthèse Historique y, más aún, con la de los creadores de la revista Annales, Bloch y Febvre ${ }^{10}$. Ellos se propusieron que sus estudios históricos tratasen sobre todo de colectividades, y de su lado menos conocido (sobre todo el inconsciente, lo anodino o no advertido); y que se incluyese también todo cuanto se refiere a las 'mentalidades' o vivencias del momento, no sólo a los hechos en sí. Parece probado que, como tales historiadores, se hicieron eco de las críticas de fin de siglo de la escuela sociológica de Durkheim a las insuficiencias de los trabajos históricos entonces vigentes, en pleno positivismo, por no proceder a estudios comparados y de fenómenos colectivos:

Dans la préface au premier numéro de l'Année Sociologique Durkheim écrit: -L'histoire ne peut être une science (que) dans la mesure où elle explique et on ne peut expliquer qu'en comparant. Or, dès qu'elle compare devient indistincte de la sociologie" (Burguière, 1991: 69) ${ }^{11}$.

Yo creo que los contactos con la escuela de Durkheim fueron más directos de lo que nos propone $\mathrm{A}$. Burguière, pues tengo en mi poder un pequeño volumen de 1930 , en que se contienen varias conferencias sobre la palabra y la idea de "civilización", en las que participa Marcel Mauss con Henry Berr y Lucien Febvre ${ }^{12}$. De este hecho, se deduciría

10 En favor de esta tesis, Cf. André Burguière (1991). Se trata de un número dedicado a las revistas etnológicas del sur de Europa (Francia, España, Portugal, Italia y Túnez), con participación numerosa de España, en particular de este Departamento del CSIC.

" El paréntesis es nuestro, agregando una particula necesaria. La revista durkheimiana se inicia en 1897, casi el mismo año que la nueva serie de la famosa American Antbropologist, cuando comienza a ser controlada por los hombres de Boas, como ha probado George W. Stocking (1968).

12 Se trata de la primera de las "semanas internacionales de síntesis", promovidas por $\mathrm{H}$. Berr en sentido interdisciplinar, a las que se refiere F. Braudel en la p. 212 del libro antes citado, como precedentes de los encuentros interdisciplinares conseguidos en los 'estudios de área' norteamericanos, organizados en la postguerrra. La conferencia de Mauss se dio el viernes 24 de mayo de 1929 bajo el título -Les civilisations: élements, formes et aires de civilisations. La de Febvre ${ }^{C} \mathrm{C}$. Histoire du mot; evolution du sens". Hay otra de P. Rivet sobre .Evolution. L'evolution de l'espèce humaine. Al parecer, se trataba del acto de inauguración oficial del Centro Internacional de Síntesis, de $\mathrm{H}$. Berr. Recuérdese que es el año mismo en que se fundan los Annales. 
que el sentido de las varias civilizaciones que ha tenido la humanidad - como consciencia historiográfica que trasciende la historia meramente occidental como objeto propio, y les concede el mismo rango-, y la consecuente influencia durkheimiana y antropológica en la generación de historiadores de los Annales, efectivamente se habría producido -como sostiene A. Burguière- desde el principio, y no en la generación de postguerra liderada por Braudel, como se acepta normalmente.

Aparte del mundo norteamericano y francés, la colaboración entre la antropología y la historia se ha dado también en el mundo inglés. De un modo muy parecido a como Durkheim atacaba el castillo histórico, el historiador inglés Maitland sentenciaba: "La antropología será historia, o no será nadan. Con ello estaba quejándose de la reacción que había tenido en los años veinte la antropología inglesa desentendiéndose de la historia, que era confundida o con las conjeturas evolucionistas (estadios necesarios en secuencias unilineales) o con las de los difusionistas (ciclos culturales diferentes, pero igualmente necesarios), o con conocimientos eruditos acerca del pasado remoto de las sociedades europeas: cosas que Malinowski o Radcliffe-Brown creían que no resolvían nada en su trabajo funcionalista sobre las sociedades primitivas. Siguiendo un patrón de ciencia natural —según modelo durkheimiano-, la antropología funcionalista se plantea seriamente la posibilidad de tomar los datos directamente del terreno por observación propia ( $\mathrm{y}$ en la lengua nativa), de intentar una explicación de cada fenómeno dentro del conjunto institucional a que pertenece, y de asumir que todo lo que se cuente del pasado vale sólo por su función presente. Las historias que operan en su trabajo son las que procedan de la propia sociedad, y éstas no tienen tanto un valor histórico como cultural (expresan leyendas, mitos, racionalizaciones presentes, etc.).

No es el momento de cuestionar ahora la importancia trascendental que tuvieron los estudios funcionalistas para la constitución profesional de la disciplina (Malinowski y su trabajo de campo en las Trobriand entre 1914 y 1918 es el paso del Rubicón en este proceso, el punto de no retorno). Pero el énfasis en las funciones de cada elemento y el valor del mundo presente trajo a cambio un cierto olvido de la vertiente histórica de la vida social, de los procesos y transformaciones, y de los casos particulares. Por ello, E.E. Evans-Pritchard, el sucesor de Radcliffe-Brown en Oxford (discípulo suyo, y antes de Malinowski, en Londres), creyó llegado el momento en 1950 de cambiar el rumbo de la escuela, y se declaró en contra de la concepción de la antropología como ciencia natural y, por tanto, de la conocida versión a-histórica de sus maestros: 
Personalmente no hallo ninguna razón válida para considerar un sistema social en la misma categoría que un sistema orgánico o inorgánico (...) es inútil, y lleva únicamente a una serie de discusiones sobre métodos, sin resultados prácticos (...) Si bien critico algunas de las hipótesis fundamentales del funcionalismo, no deseo que se crea que no soy un funcionalista y un continuador de mis maestros, los profesores Malinowski y Radcliffe Brown (...) Lo que estoy discutiendo es la importancia que tiene la historia de las instituciones sociales para un estudio de las mismas (...)

El asunto que acabamos de tratar está adquiriendo cada vez mayor importancia, pues los antropólogos sociales han comenzado a estudiar algunas sociedades pertenecientes a culturas históricas (...) (las comunidades campesinas en la India y Europa, los nómadas árabes y otras comunidades similares, y ya no aborígenes australianos o de los mares del Sur).

Se podría hablar mucho sobre este asunto, pero ustedes pensarán que se trata de una querella doméstica, que sería más bien tema para una reunión de especialistas (...) considero, junto con otros colegas y en contra de la opinión de la mayoría de ellos en este país, que esa disciplina (de la antropología social) pertenece más al dominio de las humanidades que al de las ciencias naturales.

A mi parecer, la antropología social se asemeja más a ciertas ramas de estudios históricos - historia social y la historia de las instituciones y de las ideas, con preferencia a la historia narrativa y política- que a cualquiera de las ciencias naturales (...) Estoy de acuerdo con el profesor Kroeber (.History and Science in Anthropology", Amer. Anthrop., 1935) en que las diferencias que acabamos de mencionar - documentos y diacronía- son diferencias de técnica, insistencia y perspectiva, y no de finalidad o procedimiento. La historiografía y la antropología social emplean el mismo método de integración descriptiva, si bien (ésta) (...) tiende a la comparación y generalización de manera más explícita e intencional que la otra (1967: 74-77) ${ }^{13}$.

Como se ve, Evans-Pritchard se atreve a postular claramente una posición favorable a la articulación entre antropología e historia, más bien que con las ciencias naturales, y lo justifica por cuestión de método (cree que la antropología pertenece a las humanidades) y por razones prácticas, ya que los antropólogos han comenzado a estudiar sociedades con documentos. Es exactamente la posición que adoptaría luego Julio Caro Baroja, que estaba por aquella época en Oxford, en compañía de su amigo Julian Pitt-Rivers, discípulo directo de Evans-Pritchard ${ }^{14}$.

13 Es la traducción castellana de una serie de conferencias en la BBC en 1950, en que se aprovechan trabajos contemporáneos del autor, entre otros la citada conferencia Marett en el Exeter College de Oxford de junio de ese año, Evans-Pritchard (1950).

14 Cf. el recuerdo de esta visita de 1952 a Oxford en Caro (1972: 506-7). Curiosa conclusión la suya: "no entré en su escuela o grupo porque yo he sido en esencia un historiador... nunca he podido escribir nada sin pensar en profundidades temporales y en irregularidades, disarmonías y contradicciones. No tengo una mente teológica ni sociológica... me cuesta mucho encontrar el orden donde sea. 


\section{UN CAPITULO APARTE. LA HISTORIA DE LA ANTROPOlOGÍA}

Coherentemente con esta preocupación por la historia, Evans-Pritchard tuvo siempre un gran interés por la historia de la antropología, como mostró en estas conferencias y en otras de carácter introductorio, y también en un libro póstumo, que ha sido recientemente traducido: Historia del pensamiento antropológico (1987). No se trata, como indica el prologuista, de una historia profesional sino de apuntes personales, cargados de apasionadas adhesiones o descalificaciones: "Evans-Pritchard no escribe como historiador, sino que se involucra en una polémica vivan. De hecho, el mismo autor se olvida de este punto - la historia de la antropología-, cuando pasa revista en una conferencia de 1961 sobre la historia y la antropología a los campos de colaboración. A lo más que llega es a admitir una sociología de la historia, y otra de la antropología: "puesto que las investigaciones, los datos y las inferencias obtenidas también cambian de generación en generación" (1974). Quizá sean las historias que cabe esperar de un profesional, como nos advierte Thomas Kuhn:

\footnotetext{
Al igual que las antiguas historias de las ciencias físicas, esta literatura es a menudo indispensable, pero como historia comparte sus limitaciones (...) Las publicaciones preliminares de Stocking sobre historia de la antropología americana proporcionan un ejemplo particularmente fecundo de la perspectiva que el historiador general puede aplicar a un campo específico cuyos conceptos y vocabulario sólo muy recientemente se han tornado esotéricos (1974: 316b).
}

Lo que expone Kuhn afecta no sólo a las relaciones de la historia con la antropología sino con todas las ciencias -él pone el ejemplo de la suya, la física-. Son las diferencias entre historiadores y científicos, sobre todo cuando éstos hacen su propia historia disciplinar. Es decir -si se me permite autocitarme (1984: 19)- "intención fundamentalmente pedagógica, selección de unos cuantos héroes de cada época sin relación real con su propio tiempo ni entre sí, preferencia de las analogías con el presente en autores y teorías, utilización partidista a efectos genealógicos, descuido metodológico de los materiales originales y la prueba documental, etc.". Ahora bien, en el caso de la antropología, la entrada de un historiador profesional como Stocking creó un verdadero hiato entre la manera de historiar tradicional y la que él proponía. Una discípula suya comentaba así el hiato, en una reseña especializada sobre los trabajos mundiales de historia de la antropología, y refiriéndose a la obra de su maestro:

En contra de la mayor parte de los escritos históricos de los antropólogos, los ensayos de Stocking están organizados alrededor de problemas de la historia intelectual definidos claramente; la documentación de archivo reemplaza como, 
centro de sus análisis a las fuentes fácilmente accesibles; los antropólogos individuales vienen situados dentro de un contexto social general, al igual que la misma disciplina; los juicios de valor van subordinados a la clarificación de la naturaleza de los cambios en las ideas y su forma de incorporación a través del tiempo; las generalizaciones se evitan a menos que lo permita la evidencia, cuya naturaleza es claramente establecida (Darnell, 1974: 402) ${ }^{15}$.

Al igual que las críticas post-modernas (con las que Stocking está relacionado, sin ser claro partidario), las críticas historiográficas de Stocking y su escuela al modo de historiar su propia profesión causaron impacto en su propio país. Es muy conocido su artículo "Sobre los límites del presentismo..." (1965), criticando en general dentro de las ciencias sociales la actitud del científico hacia su historia como "presentista" y no historicista, como si buscasen el pasado solamente como parte del presente. Algún colega amigo suyo ha descrito como un shock la impresión causada por Stocking -y un grupo de historiadores de la ciencia, como Bock, Nagel, Merton o Gillipspie- en 1962, en una Conferencia sobre historia de la antropología convocada en Nueva York por el Consejo de Investigación en Ciencias Sociales. Su descripción permitía, irónicamente, comparar la impresión causada por Stocking a los antropólogos presentes a la que produce un antropólogo en una tribu: sorprendiéndoles por tomarse sus propias tradiciones al modo de un presuntuoso extranjero (incluso, como un peligroso iconoclasta), y no simplemente como se las dictaban ellos mismos ${ }^{16}$.

La misma impresión ha causado fuera de EE.UU. la irrupción de un historiador - aparte de ello, de origen americano, y que se permite 'construir' de nuevo la historia inglesa de la antropología clásica, la victoriana-, especialmente en la tribu antropológica inglesa, que se siente la abuela internacional del recién nacido. Precisamente, el primer presidente de la European Association of Social Anthropologist, Adam Kuper, ha salido al encuentro de Stocking en un artículo reciente (1991), cuestionando la 'petición de principio' del historiador norteamericano de que los antropólogos hacen mal su historia, porque son 'presentistas' ${ }^{17}$. Los argumentos de Kuper son sofisticados, pero se resumen en la valoración 'emic'

is La misma autora ha recogido también una antología excelente sobre teorías y ensayos historiográficos de la antropología (1977).

16 Informe de Dell Hymes a la Asamblea Anual de la Sociedad Antropológica Kroeber, de California. En R. Darnell (1977: 298 y ss.).

17 Este artículo ha sido traducido por Arturo Álvarez, como *Historia de la antropología como discurso teórico, para publicar en las Actas del Congreso de Antropología de Granada, 1990, donde el autor lo leyó en inglés como conferencia inaugural. Como se sabe, estas actas están inéditas aún. 
de la propia historia, -es decir, la visión del actor- que los antropólogos siempre han considerado de alto valor en sus informantes. Sin embargo, al igual que no basta tal versión como explicación antropológica -como visión 'etic'-, no deberíamos ahora, en buena lógica, conformarnos en nuestro caso con nuestra visión indígena. Bien es verdad que los antropólogos-lectores de tales historias pueden tener gustos propios, como expresa Kuper:

Por supuesto no pretendo cuestionar el punto ineludible de que la historia debe ser tomada seriamente por quienes la escriben, si ha de ser de valor para aquéllos que la leen. Mi argumento es simplemente que mucha gente que lee la historia de la antropología son profesionales, y que para dirigirse a ellos un profesional puede tener ventajas sobre uno de fuera.

Pero, como ya he defendido en otro lugar (1994), daríamos una prueba de coherencia antropológica si aceptáramos la crítica a nuestro presentismo historiográfico, del mismo modo como queremos que se acepten nuestras propias críticas al etnocentrismo con que la historiografía ha considerado los fenómenos exóticos de que nos ocupamos (cultura popular, minorias culturales, etc.). Pero además, creo que tenemos en nuestra propia tradición un principio de 'relativismo cultural', derivado del holismo categórico en que nos movemos (por el que cada cosa debe ser vista dentro del conjunto real a que pertenece), que es perfectamente equiparable a la propuesta 'historicista' que nos hace la historiografía: es decir, no quitarles a los hechos su propio lenguaje y contexto. Independientemente del valor presente que quepa atribuirles.

Creo que, al igual que en el debate comparado de las ciencias -entre las ciencias básicas y aplicadas, a propósito de su mayor utilidad presente-, la insistencia excesiva en el presente puede terminar siendo un arma de doble filo ¿Cómo sabremos el valor final de nuestras investigaciones hasta que concluyan? ¿No serán las propuestas utópicas de hoy las soluciones de mañana? ¿No valdrá lo mismo para las Humanidades, hoy en evidente postergación?

\author{
FERMIN DEL PINO DIAZ \\ Instituto de Filología \\ CSIC, Madrid
}




\section{BIBLIOGRAFÍA}

ARGUEDAS, JOSE M. ${ }^{2}$, 1990: El zorro de arriba y el zorro de abajo. Edición crítica de EveMarie Fell. Colección Internacional de Archivos, Madrid: CSIC.

Ballesteros, ANTONIO, 1942: "Don Juan Bautista Muñoz. La Historia del Nuevo Mundo", Revista de Indias, 10, 589-660.

Braudel, Ferdinand, 1968: La bistoria y las ciencias sociales. Selección de Felipe Ruiz Martín y traducción de Josefina Gómez Mendoza, Madrid: Alianza Editorial (incluye seis trabajos entre 1950 y 1960 ).

BURGUIĖRE, ANDRÉ, 1991: "L'aventure des Annales: histoire et ethnologie", Hésiode. Cabiers d'ethnologie méditerrenéenne, 1, 59-72.

Caro Baroja, Jullo, 1972: Los Baroja, Madrid: Taurus.

- 1993: De Etnología andaluza. Edición y prólogo de Antonio Carreira, Málaga: Diputación Provincial de Málaga, Colección Monografías, n. ${ }^{\circ} 5,588 \mathrm{pp}$.

DARNELL, REGNA, 1974: "History of anthropology in historical perspective", Annual Review of Anthropology, 6, 399-417.

- 1977: Readings in the history of Antbropology, New York: Harper and Row Publishers.

EVAnS-Pritchard, E. E., 1950: “Anthropology: past and present, Man, 198.

- 1967: Antropología social, Buenos Aires: Ediciones Nueva Visión.

- 1974: Ensayos de Antropología Social, Madrid: Siglo XXI.

- 1987: Historia del pensamiento antropológico. Recopilación de André Singer. Introducción de Ernest Gellner, Madrid: Cátedra.

Febvre, L. y otros, 1930: Civilisation. Le Mot et l'idée. Exposés para L. Febure, E. Tonnelat, $M$. Mauss, $A$. Niceforo et $L$. Weber. Première Semaine Internationale de Synthèse, Paris: La Renaissance du Livre. Deuxième fascicule.

FOSTER, GEORGE, 1959: "Cofradía y compadrazgo en España e Hispanoamérica”, Revista del Museo Nacional, Lima, XVIII.

- 1962: Cultura y Conquista, México: Universidad de Veracruz.

GREENWOOD, DAVYDD, 1992: "Las antropologías en España: una propuesta de colaboración, Antropologia. Revista de pensamiento antropológico y estudios etnográfi$\cos , 3,5-33$.

KuHN, ThOmas, 1974: "Historia de la ciencia", Enciclopedia Internacional de Ciencias Sociales, Madrid: Aguilar, 2, 313-321.

KUPER, ADAM, 1988: The invention of Primitive Society. Transformation of an Illusion, London: Routledge.

- 1991: "Anthropologists and the history of Anthropology", Critique of Anthropology, $11: 2,125-142$.

LÉvi-STRAuss, C., 1961: "La crise de l'anthropologie moderne", Le Courrier de l'UNESCO, año 14, n. ${ }^{\circ} 11$.

- 1986: Antropologia estructural. Mito, Sociedad. Humanidades, México: Siglo XXI, $5 .^{2}$ edición.

LLOBERA, JOSEP R., 1975: La antropología como ciencia. Textos... compilados y prologados por .... Barcelona: Anagrama.

- 1990: La identidad de la antropología, Barcelona: Anagrama, Col. Argumentos (finalista del Premio Anagrama de Ensayo).

MerCIer, PAul, 1969: Historia de la antropologia, Barcelona: Ediciones Península. (Orig. 1966). 
MORENO, ISIDORO, 1986: -Trabajo de campo antropológico en el sur de Europa y colonización científica: el caso de Andalucía., XIII European Congress for Rural Sociology, Braga (Portugal).

ORTEGA, Julio (coord.), 1983: Número especial dedicado a José María Arguedas. Revista Iberoamericana, XIIX, n. ${ }^{\circ} 122$.

Pino Díaz, FERmín, 1984: "Repercusiones de la nueva historiografía de las ciencias en el campo de la Etnología: el problema de la profesionalización., Alcaveras. Revista de Antropología, 4, 19-22.

- 1991: "Antropología, colonialismo y minorías culturales", Antropología. Revista de pensamiento antropológico y estudios etnográfricos, 1, 5-26.

- 1994: :Por una historia antropológica de la antropología", en RICARDo SANMARTín (coord.), Antropología sin fronteras. Ensayos en bonor a Carmelo Lisón, Madrid: Centro de Investigaciones Sociológicas, 561-578.

Rovira, José CARlos, 1992: José Maria Arguedas. Una recuperación indigenista del mundo peruano. Una perspectiva de la reación latinoamericana. Presentación y selección de textos de... Suplementos de la Editorial Anthropos, $\mathrm{n}^{2} 11$. Barcelona.

SEGUNDAS JORNADAS DE ANTROPOLOGÍA DE MADRID, 1991: Malestar cultural y conflicto en la sociedad madrileña, Madrid: Comunidad de Madrid y Asociación Madrileña de Antropología.

STEWARD, JULIAN (ed.), 1946-49: Handbook of South American Indians, Washington: Bureau of American Ethnology, Smithsonian Institution, 6 vols.

STOCKING, GEORGE W., 1965: "On the limits of Presentism and Historicism in the historiography of the Behavioral Sciences", Journal of the History of the Behavioral Sciences, 1, 211-218.

- 1968: Race, Culture and Evolution. Essays in the History of Anthropologv, New York: The Free Press.

Las relaciones entre la antropología y la historia han estado marcadas por una competencia por establecer sus fronteras, pero también por un reiterado proceso de préstamos mutuos. Entre antropólogos ha surgido una Etnohistoria -más que la historia propia, la que resulta de los documentos ajenos, los europeos generalmente-, y entre historiadores una Antropología histórica - dedicada a las capas sociales minoritarias o a los segmentos de la vida menos conscientes-. Por último, a la hora de hacer su historia, los antropólogos - como otros científicos- han tenido que echar mano de la historiografía profesional para verse mejor, sin tribalismo presentista.

The relations between anthropology and history have been characterized by the rivalry in the definition of their limits, but also by a continuous process of mutual borrowings. Among the anthropologists emerged ethnohistory - the history from the foreign, usually european records, rather than our own history - and among the historians arose historical anthropology - devoted to the ethnic minorities or to the more devoid levels of mental conscience. Finally, when anthropologists tried to make their own history they were forced -as it is also the case with other scientists - to resort to professional historiography as the only way to look at themselves preventing the presentist tribalism. 